\title{
Magnesium Sulphate Agitation Management Effectiveness in Cases of Endoscopic Sinus Surgical Interventions
}

\author{
Mohamed Sayed Fahim* \\ Intensive Care and Pain Management Department, Faculty of Medicine, Egypt \\ *Corresponding author: Mohamed Sayed Fahim, Anesthesia, Intensive Care and Pain Management Department, Faculty of Medicine, \\ Ain Shams University, Egypt, Email: Mohamed.fahem@med.asu.edu.eg
}

\begin{abstract}
Background: A bloodless field is one of the aims to enhance the visualization during the endoscopic sinusoidal procedure that is usually achieved by controlled hypotension permitting easier dissection. The value of magnesium sulfate as an agent that could reduce the agitation issues postoperative still requires research efforts to be compared to placebo as regards endoscopic sinus surgical interventions.

Aim: To investigate the effectiveness of magnesium sulphate in treatment of postoperative agitation following functional endoscopic sinus surgery.

Methodology: A prospective clinical research trial that recruited 210 research study subjects scheduled for sinus endoscopic surgeries Cases have been categorized in a random manner into two research groups equally numbered one research group have been administered intraoperative magnesium sulphate and the other group $0.9 \%$ saline solution.

Results: The comparative statistical analysis between magnesium group and control group regarding RASS score(Richmond agitation-sedation scale) at different time of measurement and incidence of agitation at 0 min in which the RASS score was statistically significantly lower among magnesium research group at $0,5,10,15,20,25,30$, total ( $p$ values $0.008,<0.001,<0.001,0.005,0.008$, $0.013,0.020,<0.001$ consecutively) Incidence of agitation at $0 \mathrm{~min}$ was statically significantly lower among the magnesium research group ( $\mathrm{p}$ value $=0.019$ )

Conclusion: Magnesium sulphate administration is a useful agent in reducing the agitation issues in endoscopic sinus surgical procedure; however, the current research study results should be verified by future research efforts in a multicenter manner.
\end{abstract}

Keywords: Magnesium sulphate; Agitation; Endoscopic sinus surgical interventions

\section{Introduction}

Endoscopic surgical approaches for management of sinonasal diseases have become a widely spread intervention surgery however a trivial bleeding amount could greatly affect the visibility during endoscopic sinus surgical interventions raising the estimated risk of complications and converting the level of challenge to more difficult levels [1-4]. A bloodless field is one of the aims to enhance the visualization during the endoscopic sinusoidal procedure that is usually achieved by controlled hypotension permitting easier dissection [5-7]. Hypotension even in controlled manner could have its undesirable impacts and various agents have been investigated and upgraded to reduce the side effects e.g. beta-blockers, sodium nitroprusside, and magnesium sulfate $[8,9]$. Furthermore agitation within the Postoperative time period even though have a short time interval carries serious sequlae if not properly managed such as liability for self-injury due to dislodgement of intravenous lines and nasal packs, causing serious bleeding issues.The value of magnesium sulfate as an agent that could reduce the agitation issues postoperative still requires research efforts to be compared to placebo as regards endoscopic sinus surgical interventions [1013].

\section{Aim of the work}

To investigate the effectiveness of magnesium sulphate in treatment of postoperative agitation following functional endoscopic sinus surgery.

\section{Methodology}

A randomized (using computer-generated random allocation) double-blinded clinical; research trial conducted from May 2017 till May 2019, after approval of local ethical committee on the current research study and written informed consent was taken from all participant, conducted at Mohamed Saleh Bashrahil Hospital in Holy Makka, Saudi Arabia. A prospective clinical research trial 
that recruited 210 research study subjects Inclusion criteria Patients of either sex aged between 18 and 65 years, American Society of Anesthesiologists' physical status I or II and scheduled for sinus endoscopic surgeries, Exclusive research criteria were as follows cases having hypertension, myocardial ischemia, Transient ischemic attacks history, pregnancy, under treatment by calciumchannel blocking agents, DM, allergic reaction to magnesium compounds. Cases have been categorized in a random manner into two research groups equally numbered one research group have been administered intraoperative magnesium sulfate and the other group $0.9 \%$ saline solution. Every $10 \mathrm{ml}$ of magnesium solution contained 1000mg of magnesium (PSI, Jeddah, Saudi Arabia). For each patient, a total dose of magnesium sulphate of $60 \mathrm{mg}$ per $\mathrm{kg}$ have been diluted in $20 \mathrm{ml}$ saline, Patients in the magnesium group received an initial intravenous loading dose of $30 \mathrm{mg}$ per kg over $1 \mathrm{~h}$, followed by a continuous infusion of $9 \mathrm{mg}$ per kg per hour. (Syringe pump Terumo, TE-SS800, Japan) for the duration of surgery. The control research group was administered an equal volume of $0.9 \%$ saline.

For preanaestehtic medication all patients were administered atropine $0.5 \mathrm{mg}$ and promethazine $25 \mathrm{mg}$ intramuscularly one hour before the induction time. An arterial catheter was used for measuring arterial pressure throughout the procedure. Standard monitoring (Carescape Monitor B650, GE electric, Finland) have been conducted and involved pulse oximetry (Sp02), noninvasive blood pressure, ECG and heart rate, end-tidal CO2 concentration and Bispectral Index (BIS) to rule out intraoperative awareness which may take part in post-operative agitation.Anesthetic induction agents used were Propofol $2.5 \mathrm{mg}$ per $\mathrm{Kg}$ and fentanyl $1.5 \mathrm{Ug}$ per $\mathrm{Kg}$ followed by atracurium for tracheal intubation $0.5 \mathrm{mg}$ per $\mathrm{kg}$. Then Mechanical ventilation was commenced (Datex Omeda, Aespire view, Madison, WI, USA) and anesthesia was maintained with a sevoflurane concentration of $2 \%$ in a N20/02 mixture (1/1 L. per min.). Neuromuscular block was maintained with Atracurium $0.3 \mathrm{mg} / \mathrm{kg} / \mathrm{h}$. under neuromuscular transmission (NMT) mechanoSensor monitor Nitroglycerine (Nitrocin, $5 \mathrm{mg} / \mathrm{ml}$, SAMARTH LIFE SCIENCES PVT. LTD, INDIA) was infused during surgery at a rate of 5 to $10 \mathrm{mg} / \mathrm{kg} / \mathrm{min}$ with the aim of maintaining a mean arterial BP (MAP) of $58 \pm 5 \mathrm{mmHg}$ to reduce bleeding and improve the surgical field. After completion of the surgery, full muscle reversal, tracheal extubation and stoppage of all

\section{Results}

Table 1: Demographic, characteristics and preoperative measures between the two studied groups.

\begin{tabular}{|c|c|c|c|c|c|c|}
\hline & Total No. $=\mathbf{2 1 0}$ & Magnesium No. = 105 & Control No. $=105$ & Test value & P-value & Sig. \\
\hline Age (years) & $33.20 \pm 8.03$ & $32.28 \pm 8.42$ & $34.11 \pm 7.63$ & $1.650^{*}$ & 0.1 & NS \\
\hline Male gender, no. (\%) & $116(55.24 \%)$ & $55(52.38 \%)$ & $61(58.1 \%)$ & $0.693^{*}$ & 0.405 & NS \\
\hline Smoking, no. (\%) & $88(41.91 \%)$ & $42(40.0 \%)$ & $46(43.8 \%)$ & $0.313^{*}$ & 0.575 & NS \\
\hline BMI $\left(\mathrm{kg} / \mathrm{m}^{2}\right)$ & $29.65 \pm 7.05$ & $28.85 \pm 6.74$ & $30.44 \pm 7.36$ & $1.633^{*}$ & 0.104 & NS \\
\hline Pre-op MABP (mmHg) & $89.69 \pm 9.01$ & $88.62 \pm 8.89$ & $90.75 \pm 9.13$ & $1.713^{*}$ & 0.088 & NS \\
\hline Intra-op MABP (mmHg) & $58.16 \pm 5.05$ & $58.65 \pm 4.63$ & $57.67 \pm 5.46$ & $1.403^{*}$ & 0.162 & NS \\
\hline PACU MABP (mmHg) & $94.53 \pm 5.90$ & $93.92 \pm 6.41$ & $95.13 \pm 5.38$ & $1.482^{*}$ & 0.14 & NS \\
\hline PACU SpO2 (\%) & $99.16 \pm 0.75$ & $99.13 \pm 0.7$ & $99.18 \pm 0.8$ & $0.482^{*}$ & 0.63 & NS \\
\hline ET Co2 (kPa) & $4.75 \pm 1.00$ & $4.8 \pm 1.1$ & $4.7 \pm 0.9$ & $0.721^{*}$ & 0.472 & NS \\
\hline
\end{tabular}

Citation: Mohamed Sayed Fahim. Magnesium Sulphate Agitation Management Effectiveness in Cases of Endoscopic Sinus Surgical Interventions. Glob J Anes \& Pain Med 2(2)-2019. GJAPM.MS.ID.000131. DOI: 10.32474/GJAPM.2019.02.000131. infusions, cases have been administered ephedrine hydrochloride $10 \mathrm{mg}$ intravenously to restore the mean arterial pressure to the preoperative reading.

Patients were then shifted to the postanaesthesia care unit (PACU), paracetamol 1g (Paracetol; Pharmaceutical Solutions Industry, Jeddah, KSA) was given intravenously. Thirty minutes after admission to PACU, and when agitation and pain score recordings taken, incremental doses of pethidine $25 \mathrm{mg}$ were given intravenously (not to interfere with agitation recordings) every $10 \mathrm{~min}$ as rescue analgesia, targeting a pain score 2 or less. Agitation was assessed on 0 and 5, 10, 15, 20, 25 and 30min. Postoperative agitation have been evaluated using Richmond agitation-sedation scale (RASS): 0, alert and calm; 1, restless (anxious or apprehensive but movements not aggressive or vigorous); 2, agitated (frequent non purposeful movement); 3 , very agitated [pulls on or removes tube(s) or catheter(s) or has aggressive behavior towards staff] and 4 , combative(overtly combative or violent, immediate danger to staff). The main research outcome was the frequency and severity of agitation at all times within the post-operative recovery timing from 0 till 30min. Secondary outcomes were Post-operative pain score, PACU stay, Total Nitroglycerine \& pethidine doses.

\section{Statistical analysis}

Power analysis was based on a pilot study comparing the frequency of agitation 5 min after PACU admission as a primary determinant of sample size. Using the difference in the means between the two groups, given a probability $=0.05$, power $95 \%$, revealed that a total sample size of 210 was required (105 per group) to detect a $50 \%$ reduction in agitation. Data were collected, revised, coded and entered to the Statistical Package for Social Science (IBM SPSS) version 23. The quantitative data were presented as mean, standard deviations and ranges when parametric and compared between the two groups using Independent t-test while nonparametric were presented as median with inter-quartile range (IQR) and compared between the two groups using Mann-Whitney test. Also, qualitative variables were presented as number and percentages and compared between the two groups using Chisquare test and/or Fisher exact test when the expected count in any cell found less than 5 . The confidence interval was set to $95 \%$ and the margin of error accepted was set to $5 \%$. So, the p-value was considered significant at the level of $<0.05$. 


\begin{tabular}{|c|c|c|c|c|c|c|}
\hline IV fluids & $2.23 \pm 0.47$ & $2.25 \pm 0.51$ & $2.21 \pm 0.42$ & $0.620^{*}$ & 0.538 & NS \\
\hline Duration of surgery (min) & $132.79 \pm 10.29$ & $133.81 \pm 10.75$ & $131.76 \pm 9.82$ & $1.443^{*}$ & 0.151 & NS \\
\hline Total NG dose (mg) & $56.29 \pm 19.82$ & $43.86 \pm 18.91$ & $68.72 \pm 20.72$ & $9.081^{*}$ & $<0.001$ & HS \\
\hline NG (mg.kg ${ }^{-1}$ min- $^{-1}$ ) & $12.25 \pm 1.76$ & $10.65 \pm 1.88$ & $13.84 \pm 1.64$ & $13.102^{*}$ & $<0.001$ & HS \\
\hline PACU stay (min) & $104.26 \pm 19.90$ & $93.12 \pm 17.69$ & $115.39 \pm 22.1$ & $8.061^{*}$ & $<0.001$ & HS \\
\hline Pain scale, median (IQR) & $5(3-7)$ & $4(3-5)$ & $6(4-7)$ & $3.658 \neq$ & 0.009 & HS \\
\hline Pethidine dose (mg) & $10.30 \pm 2.04$ & $11.63 \pm 1.97$ & $8.97 \pm 2.1$ & $9.466^{*}$ & $<0.001$ & HS \\
\hline
\end{tabular}

Reveals and displays the Demographic, characteristics and preoperative measures between the two studied groups in which Age (years), Male gender, no. (\%) Smoking, no. (\%) BMI (kg/m²), Preop MABP (mmHg), Intra-op MABP (mmHg), PACU MABP (mmHg). PACU SpO2 (\%), ET Co2 (kPa), IV fluids, Duration of surgery (min) in which there was no statistical significant difference between

Table 2: Comparison between magnesium group and control group regarding RASS score at different time of measurement and incidence of agitation at $0 \mathrm{~min}$.

\begin{tabular}{|c|c|c|c|c|c|}
\hline RASS & Magnesium & Control & $\begin{array}{c}\text { Test } \\
\text { value } \neq\end{array}$ & P-value & Sig. \\
\hline & No. $=105$ & No. $=105$ & & & \\
\hline $0 \mathrm{~min}$ & $2(0-2)$ & $3(0-3)$ & 3.871 & 0.008 & HS \\
\hline $5 \mathrm{~min}$ & $2(0-2)$ & $3(0-3)$ & 4.632 & $<0.001$ & HS \\
\hline $10 \mathrm{~min}$ & $1(0-2)$ & $2(0-3)$ & 5.18 & $<0.001$ & HS \\
\hline $15 \mathrm{~min}$ & $1(0-1)$ & $1(0-2)$ & 3.647 & 0.005 & HS \\
\hline $20 \mathrm{~min}$ & $1(0-1)$ & $1(0-2)$ & 3.435 & 0.008 & HS \\
\hline $25 \mathrm{~min}$ & $0(0-1)$ & $1(0-1)$ & 3.212 & 0.013 & $\mathrm{~S}$ \\
\hline $30 \mathrm{~min}$ & $0(0-1)$ & $1(0-1)$ & 3.123 & 0.02 & $S$ \\
\hline Total & $7(0-10)$ & $12(0-15)$ & 6.321 & $<0.001$ & HS \\
\hline $\begin{array}{l}\text { Incidence } \\
\text { of agitation } \\
\text { at } 0 \mathrm{~min}\end{array}$ & & & $5.486^{*}$ & 0.019 & S \\
\hline Negative & $43(41.0 \%)$ & $\begin{array}{c}27 \\
(25.7 \%)\end{array}$ & & & \\
\hline Positive & $62(59.0 \%)$ & $\begin{array}{c}78 \\
(74.3 \%)\end{array}$ & & & \\
\hline
\end{tabular}

Table 3: Comparison between magnesium group and control group regarding incidence of severe agitation at different time of measurement.

\begin{tabular}{|c|c|c|c|c|c|}
\hline $\begin{array}{c}\text { Incidence } \\
\text { of severe } \\
\text { agitation }\end{array}$ & Magnesium & Control & $\begin{array}{c}\text { Test } \\
\text { value }\end{array}$ & P-value & Sig. \\
\hline & No. $=105$ & No. $=105$ & & & \\
\hline $0 \mathrm{~min}$ & $35(33.3 \%)$ & $58(55.2 \%)$ & 10.21 & 0.001 & HS \\
\hline $5 \mathrm{~min}$ & $19(18.1 \%)$ & $44(41.9 \%)$ & 14.172 & $<0.001$ & HS \\
\hline $10 \mathrm{~min}$ & $10(9.5 \%)$ & $33(31.4 \%)$ & 15.47 & $<0.001$ & HS \\
\hline $15 \mathrm{~min}$ & $2(1.9 \%)$ & $13(12.4 \%)$ & 8.687 & 0.003 & HS \\
\hline $20 \mathrm{~min}$ & $1(0.95 \%)$ & $11(10.5 \%)$ & 8.838 & 0.003 & HS \\
\hline $25 \mathrm{~min}$ & $0(0.0 \%)$ & $10(9.5 \%)$ & 10.5 & 0.001 & HS \\
\hline $30 \mathrm{~min}$ & $0(0.0 \%)$ & $8(7.6 \%)$ & 8.317 & 0.004 & HS \\
\hline
\end{tabular}

both research groups ( $\mathrm{p}$ values $=0.100,0.405,0.575,0.104,0.088$, $0.162,0.140,0.630,0.472,0.538,0.151$ consecutively) however there was statistical significant difference as regards Total NG dose (mg), NG ( $\mu$ g.kg-1 min-1), PACU stay (min), Pain scale, median (IQR), Pethidine dose (mg)( $\mathrm{p}$ values $<0.001,<0.001,<0.001,0.009$, $<0.001$ consecutively)

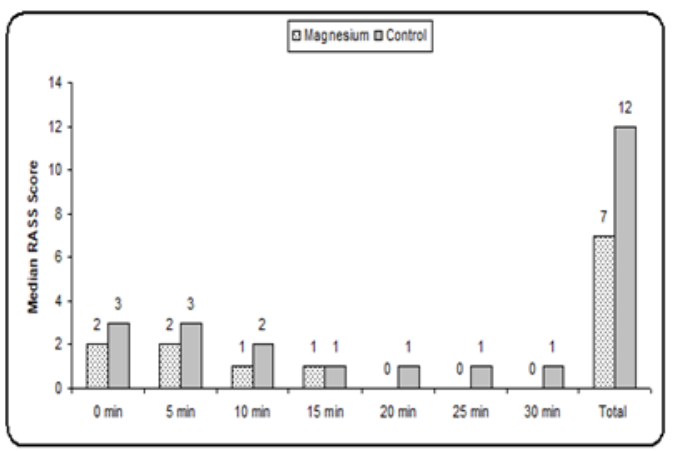

Figure 1: Comparison between magnesium group and control group regarding RASS score at different time of measurement.

Reveals and displays the comparative statistical analysis between magnesium group and control group regarding RASS score at different time of measurement and incidence of agitation at $0 \mathrm{~min}$ in which the RASS score was statistically significantly lower among magnesium research group at $0,5,10,15,20,25,30$, total ( $p$ values $0.008,<0.001,<0.001,0.005,0.008,0.013,0.020,<0.001$ consecutively) Incidence of agitation at 0 min was statically significantly lower among the magnesium research group ( $p$ value $=0.019$ )

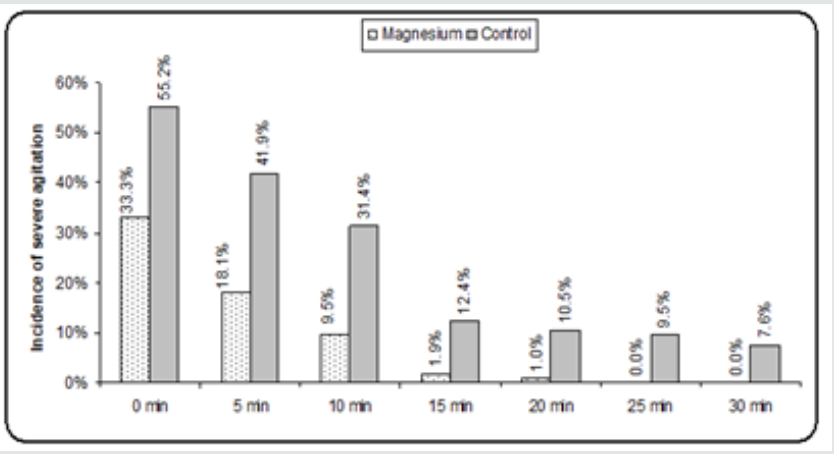

Figure 2: Comparison between magnesium group and control group regarding incidence of severe agitation at different time of measurement. 
Reveals and displays the comparative statistical analysis between magnesium group and control research groups as regards incidence of severe agitation at different time of measurement being statically significantly lower among the magnesium research group at all times $0,5,10,15,20,25,30 \mathrm{~min}$ ( $\mathrm{p}$ values $=0.001,<0.001$, $<0.001,0.003,0.003,0.001,0.004$ consecutively)

All data were presented as means and standard deviations otherwise were indicated

\section{Bold indicate significant}

•: Independent t-test; *: Chi-square test; $\neq$ : Mann-Whitney test

BMI: Body mass index; Pre-op: Preoperative; Intra-op: Intraoperative; MABP: Mean arterial blood pressure; PACU, post anesthesia care unit; ET, end-tidal; NG, nitroglycerine; NRS, numerical rating scale (for pain).

\section{Discussion}

Magnesium sulfate is a vasodilator agent implemented in every day clinical and surgical practice in a wide spectrum of uses acting by raising the Levels of prostacyclin besides it neuroprotective impact during controlled hypotension. Magnesium is a natural physiologic calcium antagonist frequently used in blood pressure control in different clinical scenarios such as preeclampsia, pheochromocytoma and reduction of blood loss volume during surgical intervention $[14,15]$. Prior research studies have revealed and displayed that magnesium sulfate reduces arterial pressure, heart rate, blood loss, and time interval required for completion of sinus surgical interventions due to its pharmacological properties. Enhanced surgical field quality was observed by prior research efforts after administration of magnesium sulfate during endoscopic sinusoidal surgical interventions [16,17]. A prior research meta-analysis have compared and contrasted between control and magnesium research groups for endoscopic sinusoidal surgical procedures and have revealed in an interesting manner that magnesium sulfate is capable to enhance the visual capacity of surgical field and decrease the volume of blood loss intraoperatively , those research results are in great harmony and similarity with the current research study results and could be justified by the fact that magnesium sulphate have hypotensive effects that could reduce the blood loss in a remarkable pattern during performance of endoscopic form of sinus procedures [1-7].

Magnesium sulfate could have issues observed by various investigators from prior research e.g. neuromuscular Blockage causing delayed recovery issues, however the current research study didn't investigate that issue in a satisfactory manner. on the other hand, in an interesting manner and in harmony with the current research study findings it was well demonstrated from previous research efforts that anesthesia duration is reduced after the administration of magnesium sulfate in comparison to placebo during endoscopic sinusoidal procedures that could raise the potential benefits of reduced risk of anesthetic agent exposure $[2,4,9,11]$. Furthermore a previous research have revealed that there was no episodes of hypotension, arrhythmia or reflex tachycardia during magnesium sulfate administration that would raise the safety profile of the agent however the current research study mainly focused on agitation issues and revealed the superiority of the magnesium research group as regards the aspects of agitation severity and frequency within the post-operative period and that is considered one of the safe guards against procedure failure since agitation could cause jerky patients movements that could inflict self-injury particularly in sensitive zones such as the site of sinusoidal intervention that require great caution when handling them by the clinical staff involved in the care $[12,13,17]$.

\section{Conclusions and Recommendations for Future Research}

Magnesium sulphate administration is a useful agent in reusing the agitation issues in endoscopic sinus surgical procedure, however the current research study results should be verified by future research efforts in a multicentric manner taking in consideration the comparison and contrast with other agents that could reduce the agitation issues in those category of cases.

\section{References}

1. Ginat DT (2015) Post treatment imaging of the paranasal sinuses following endoscopic sinus surgery. Neuroimaging Clin N Am 25: 653665.

2. Al-Bar MH, Ruiz JW, Casiano RR (2016) Does total intravenous anesthesia provide significant blood loss reduction compared to inhalational anesthesia during endoscopic sinus surgery? Laryngoscope 126: 19611962.

3. Amorocho MC, Fat I (2016) Anesthetic techniques in endoscopic sinus and skull base surgery. Otolaryngol Clin North Am 49: 531-547.

4. Zhou JC, Zhang JJ, Zhang W (2017) Efficacy of chitosan dressing on endoscopic sinus surgery: a systematic review and meta-analysis. EurArch Otorhinolaryngol 274: 3269-3274.

5. Carifi M (2014) Perioperative bleeding control in functional endoscopic sinus surgery. Eur Arch Otorhinolaryngol 271: 845-846.

6. El-Shmaa NS, Ezz HAA, Younes A (2017) The efficacy of Labetalol versus Nitroglycerin for induction of controlled hypotension during sinus endoscopic surgery. A prospective, double-blind and randomized study. J Clin Anesth 39: 154-158.

7. Ollila A, Vikatmaa L, Sund R (2018) Efficacy and safety of intravenous esmolol for cardiac protection in non-cardiac surgery. A systematicreview and meta-analysis. Ann Med 1-1.

8. Jangra K, Malhotra SK, Gupta A, et al. (2016) Comparison of quality of the surgical field after controlled hypotension using esmolol and magnesium sulfate during endoscopic sinus surgery. J Anaesthesiol Clin Pharmacol 32: 325-328.

9. Elsersy HE, Metyas MC, Elfeky HA (2017) Intraoperative magnesium sulphate decreases agitation and pain in patients undergoing functional endoscopic surgery: a randomised double-blind study. Eur J Anaestheisa 34: 658-664.

10. Aravindan A, Subramanium R, Chhabra A (2016) Magnesium sulfate or diltiazem as adjuvants to total intravenous anesthesia to reduce blood loss in functional endoscopic sinus surgery. J Clin Anesth 34: 179-185.

11. Mori K, Yamamoto T, Miyazaki M (2012) Effect of intrathecal magnesium sulfate solution injection via a microcatheter in the cistern magna on 
cerebral vasospasm in the canine subarachnoid hemorrhage model. $\mathrm{Br}$ Neurosurg 26: 64-68.

12. Chen C, Tao R (2018) The impact of magnesium sulfate on pain control after laparoscopic cholecystectomy: a meta-analysis of randomized controlled studies. Surg Laparosc Endosc Percutan Tech 28: 349-353.

13. Zhang J, Wang Y, Xu H (2018) Influence of magnesium sulfate on hemodynamic responses during laparoscopic cholecystectomy: a metaanalysis of randomized controlled studies. Medicine 97: e12747.

14. Zeng X, Xue Y, Tian Q (2016) Effects and safety of magnesium sulfate on neuroprotection: a meta-analysis based on PRISMA guidelines. Medicine 95: e2451.
15. Zhao J, Zhang S, Li X (2018) Comparison of minimally invasive and open transforaminal lumbar interbody fusion for lumbar disc herniation: a retrospective cohort study. Med Sci Monit 24: 8693-8698.

16. Jahanshahi J, Hashemian F, Pazira S (2014) Effect of topical tranexamic acid on bleeding and quality of surgical field during functional endoscopic sinus surgery in patients with chronic rhinosinusitis: a triple blind randomized clinical trial. PLoS One 9: e104477.

17. Belykh E, Onaka NR, Abramov IT (2018) Systematic review of factors influencing surgical performance: practical recommendations for microsurgical procedures in neurosurgery. World Neurosurg 112: e182e207.

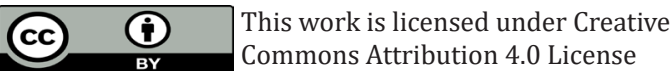

To Submit Your Article Click Here:

Submit Article

DOI: $10.32474 /$ GJAPM.2019.02.000131

$\begin{gathered}\text { Global Journal of Anesthesia } \\ \text { \& Pain Medicine }\end{gathered}$
Assets of Publishing with us
- Global archiving of articles
- Immediate, unrestricted online access
Global Journal of
Anesthesia \& Pain Medicine

